\title{
Adipose derived mesenchymal stem cells transplantation via portal vein improves microcirculation and ameliorates liver fibrosis induced by $\mathrm{CCl} 4$ in rats
}

Yu Wang ${ }^{1+}$, Fan Lian ${ }^{2+}$, Jiaping Li ${ }^{1}$, Wenzhe Fan ${ }^{1}$, Hanshi Xư ${ }^{2}$ Xiuyan Yang ${ }^{2}$, Liuqin Liang ${ }^{2}$, Wei Chen ${ }^{3}$ and Jianyong Yang ${ }^{4 *}$

\begin{abstract}
Introduction: Adipose derived mesenchymal stem cells (ADMSCs), carrying the similar characteristics to bone marrow mesenchymal stem cells, only much more abundant and easier to obtain, may be a promising treatment for liver fibrosis. We aim to investigate the therapeutic potential of ADMSCs transplantation in liver fibrosis caused by carbon tetrachloride $\left(\mathrm{CCl}_{4}\right)$ in rats as well as its underlying mechanism, and to further explore the appropriate infusion pathway.
\end{abstract}

Methods: ADMSCs were isolated, cultured and identified. Placebo and ADMSCs were transplanted via portal vein and tail vein respectively into carbon tetrachloride $\left(\mathrm{CCl}_{4}\right)$-induced liver fibrosis rats. Computed tomography (CT) perfusion scan and microvessel counts were performed to measure the alteration of liver microcirculation after therapy. Liver function tests and histological findings were estimated.

Results: CT perfusion scan shown significant decrease of hepatic arterial perfusion index, significant increased portal vein perfusion, total liver perfusion in rats receiving ADMSCs from portal vein, and Factor VIII (FVIII) immunohistochemical staining shown significant decrease of microvessels in rats receiving ADMSCs from portal vein, indicating microcirculation improvement in portal vein group. Vascular endothelial growth Factor (VEGF) was significantly up-regulated in fibrosis models, and decreased after ADMSCs intraportal transplantation. A significant improvement of liver functional test and histological findings in portal vein group were observed. No significance was found in rats receiving ADMSCs from tail vein.

Conclusions: ADMSCs have a therapeutic effect against $\mathrm{CCl}_{4}$-mediated liver fibrosis. ADMSCs may benefit the fibrotic liver through alteration of microcirculation, evidenced by CT perfusion scan and down-regulation of VEGF. Intraportal transplantation is a better pathway than tail vein transplantation.

Keywords: Adipose derived mesenchymal stem cell, Liver fibrosis, Portal venous transplantation, Computed tomography perfusion scan, Vascular endothelial growth Factor

\footnotetext{
*Correspondence: yang_jianyong@163.com

${ }^{\dagger}$ Equal contributors

${ }^{4}$ Department of Medical Imaging, the First Affiliated Hospital of Sun Yat-sen University, No. 58, Zhongshan 2nd Road, Guangzhou 510080, China

Full list of author information is available at the end of the article
} 


\section{Introduction}

Liver fibrosis representing the final common pathway of all chronic hepatic injury is a worldwide health problem $[1,2]$. Limited therapy would repair the malformation or reverse the fibrosis in progression [3], and currently the only effective available treatment for end stage hepatic fibrosis is transplantation [4].

However, a series of problems such as organ shortage, recrudescence of the original disease in transplant recipients and transplantation complications underlines the need for other antifibrotic therapeutic approaches.

Bone marrow-derived mesenchymal stem cells (MSCs) have been reported to benefit in the prevention of pulmonary fibrotic lesions [5], or ameliorate changes of liver function tests in experimental fibrosis models [6].

However, the estimated frequency of BM-MSCs in bone marrow is relatively low [7], and the interest of using other sources of MSCs has been growing.

Adipose derived mesenchymal stem cells (ADMSCs), as a source of adult mesenchymal stem cells, display similar multiple-linage differentiating potentials to bone marrow MSCs [8-11]. ADMSCs are much more abundant than BM-MSCs and easy to obtain from liposuction aspirates or excised fat. The yield from one gram adipose tissue is approximately 5,000 to 20,000 stem cells, whereas the yield from $1 \mathrm{ml}$ BM-MSCs is only $2 \%$ to $20 \%$ of ADMSCs, which makes ADMSCs a promising alternative for cytotherapy.

In the present study, we sought to test the hypothesis that transplantation of ADMSCs could effectively counteract liver fibrogenesis induced by $\mathrm{CCl} 4$ in SpragueDawley (SD) rats, improve microcirculation as well as liver function. We further investigated whether portal vein infusion was an ideal route for ADMSCs implantation.

\section{Materials and methods}

\section{Isolation, culture and identification of adipose-derived} stem cells from rat

The Sprague-Dawley (SD) rats (weight around $200 \mathrm{~g}$ ) housed under standard conditions were anesthetized and underwent lipo-dissection from inguinal fat pad. ADMSCs were isolated based on a published method described by Safford et al [12]. All experiments were approved by the Animal Experiment Committee of our University, following the Guide for the Care and Use of Laboratory Animals (National Academic Press, USA, 1996).

$100 \mathrm{mg}$ adipose tissue was taken from SD rats and digested in Hank's balanced salt solution containing $0.1 \%$ collagenase type I (Gibco, Carlsbad, CA, USA) for 1 hour at $37{ }^{\circ} \mathrm{C}$ in a centrifuge tube after carefully dissociation, followed by filtering with a $100 \mu \mathrm{m}$ cell strainer and centrifugation at $1700 \mathrm{rpm}$ for 10 minutes at room temperature, the supernatant was discarded. Dulbecco's modified Eagle's medium (DMEM; Gibco) supplemented with $10 \%$ fetal bovine serum (FBS; Gibco) were added. The resuspended cells were transferred to a culture flask and incubated in $5 \% \mathrm{CO}_{2}$ at $37{ }^{\circ} \mathrm{C}$. The medium was first replaced at 48 hours, and the nonadherent cells were removed. Rat ADMSCs at the $3^{\text {rd }}-5^{\text {th }}$ passage were identified and cultured for future experiments.

The adherent cells at $3^{\text {rd }}-5^{\text {th }}$ were trypsinized and centrifuged, fixed in neutralized $2 \%$ paraformaldehyde solution for 30 minutes. The fixed cells were washed twice and resuspended in PBS, incubated with FITClabeled anti-rat CD34, CD45, CD29, CD44 and CD90 [13,14] (all from Santa Cruz Biotech., CA) for 30 minutes. Positive cells were counted by flow cytometry with FACscan flow cytometer (Becton Dickinson, San Jose, CA).

ADMSCs at $5^{\text {th }}$ were resuspended at $2 \times 10^{6}$ cells $/ \mathrm{ml}$ in saline for autologous transplantation.

\section{Animals and treatments}

Pathogen-free male Sprague-Dawley (SD) rats (weight around $200 \mathrm{~g}$ ) purchased from the Sun Yat-sen University Animals Technology (Guangzhou China) were housed in controlled temperature of $25{ }^{\circ} \mathrm{C}$, relative humidity $\sim 70 \%$, and a $12 \mathrm{~h}$ light/dark cycle. All experiments were approved by the Animal Experiment Committee of our University, following the Guide for the Care and Use of Laboratory Animals (National Academic Press, USA, 1996). Hepatic fibrosis was induced by intraperitoneal injections of $\mathrm{CCl}_{4}$ twice a week for 12 weeks. The initial dose of $\mathrm{CCl}_{4}$ (diluted 1:1 in olive oil) was $5 \mathrm{~mL} / \mathrm{kg}$, and each subsequent dose was $3 \mathrm{~mL} /$ $\mathrm{kg}$ (diluted 1:1 in olive oil) [15]. After 12 weeks of $\mathrm{CCl}_{4}$ injury, all rats were submitted to liver function blood tests. Samples of 10 normal rats were used to define the normal control range of alanine aminotransferase (ALT) and aspartate aminotransferase (AST), albumin.

The rats presenting abnormal ALT, AST and albumin were randomly assigned to three groups forty-eight hours after the last $\mathrm{CCl}_{4}$ injection. Each group included 2 randomly picked rats for fibrosis model confirmation and 15 rats for further experiments: A) the control group without ADMSCs: $2 \times 10^{6}$ irrelevant cells (BRL-3A, a rat liver cell line) was injected in portal vein. B) The portal vein group: rats were anesthetized and exposed with an upper midline incision inferiorly from the xiphoid, and the abdominal cavity was exposed with a retractor. Portal vein was gently isolated and directly injected with $2 \times 10^{6}$ ADMSCs using a 25-gauge needle connected to a $2 \mathrm{ml}$ syringe $[15,16]$. The abdominal wall was closed after bleeding stopped by pressure. C) The tail vein group: $2 \times 10^{6}$ ADMSCs were injected in the tail vein.

$\mathrm{CCl}_{4}$ administration was continued after ADMSCs transplantation in case of spontaneous fibrosis recovery [17]. 


\section{Computed tomography perfusion imaging}

CT perfusion was performed with a 64-detector row CT scanner. (Toshiba Auqillion 64 TSX-101A, Toshiba, Tochigi, Japan). Each rat was stabled with $10 \%$ chloral hydrate and inserted with a silicone rubber tube into the tail vein for contrast injection before scanning. Plain CT scan of the abdomen was for localization of the liver, abdominal aorta and portal vein area. Scanning parameters were as follows: $120 \mathrm{kV}, 80 \mathrm{~mA}$,reconstruction field of view $90 \mathrm{~mm}$, standard reconstruction algorithm, $35 \mathrm{~cm}$ display field of view, matrix $512 \times 512$. A bolus of $0.1 \mathrm{ml} / 100 \mathrm{~g}$ of nonionic iodinated contrast medium containing $300 \mathrm{mg} \mathrm{I} / \mathrm{ml}$ (Ultravist 300, Bayer Schering, Germany) was injected into the tail vein at a rate of $1.0 \mathrm{ml} / \mathrm{s}$ and continued for 80 seconds with. 0.5 second per rotation, with four 2-mm sections acquired per rotation.

The data were then transferred to an image processing workstation (Vitrea 2, version 4.1.2.0, Vital Images, Minnetonka, MN, USA) and analyzed by two independent radiologists using Ascend CT Perfusion (Dynamic CT Perfusion System, Ascend Medical Technology, Beijing, China)., in which hepatic artery perfusion (HAP), portal vein perfusion (PVP), total liver perfusion (TLP) and hepatic arterial perfusion index (HPI = HAP / TLP, \%) were measured [18,19].

The examination was repeated at baseline, 2 days after liver fibrosis model constructed, and 6 weeks after placebo/ADMSCs infusion.

\section{Reverse transcription PCR (RT-PCR), quantitative PCR (qPCR) and western blot}

Total RNA was isolated from snap-frozen rat tissues, first-strand DNA was synthesized as previously described [20], and qPCR was performed (in triplicate reactions) using the SYBR ${ }^{\circledR}$-Green PCR Master Mix (Applied Biosystems, Applera Deutschland GmbH, Darmstadt, Germany) in the thermocycler ABI PRISM TM7700. For analysis of the VEGF, RT-qPCR was used to detect VEGF mRNA level. Primer sequences for rat VEGF were designed according to Liu et al [21].

Western blotting was used to detect VEGF protein level. Antibodies were purchased from Santa Cruz Biotechnology Inc. (Santa Cruz, CA).

\section{Histology}

Liver samples were obtained 12 weeks after the administration of $\mathrm{CCl}_{4}$ to confirm the presence of fibrosis, 18 weeks after $\mathrm{CCl}_{4}$ administration for control, and 6 weeks after ADMSCs/placebo injection. Histological analysis was conducted by a blinded fashion pathologist. The left lobe of the liver was formalin-fixed, paraffinembedded and stained with Hematoxilin \& Eosin (HE). Sirius red staining was used to assess extracellular matrix accumulation. Briefly, liver sections cut at $10 \mu \mathrm{m}$ were fixed with $4 \%$ paraformaldehyde. Extent of fibrosis were measured using an Axioplan 2 microscope (Carl Zeiss, Thornwood, NY). Five nonoverlapping fields randomly picked in per section were analyzed at $100 \times$ final magnification. Quantification of fibrotic area was expressed as the percentage of stained area in comparison to the total area of fields examined, using Image-Pro Plus 5.0 (Media Cybernetics, Bethesda, MD) image analysis software.

\section{Immunohistochemistry}

Sections from paraffin-embedded tissue $(4 \mu \mathrm{m})$ were stained with Factor VIII antibody (1:100, Santa Cruz Biotechnology Inc.) at $4{ }^{\circ} \mathrm{C}$ overnight, then incubated with biotinylated IgG at room temperature for $60 \mathrm{~min}$. Sections were then incubated with DAB and photographed with an Axioplan 2 microscope (Carl Zeiss, Thornwood, NY). The numbers of vessels less than $100 \mu \mathrm{m}$ in diameter highlighted by FVIII stained endothelial cells were counted in a blinded fashion. Five sections from each animal were scanned and averaged. The microvessel count per square millimeter after treatment was expressed as fold normal values relative to normal control.

\section{Hydroxyproline determination}

Hepatic hydroxyproline content was quantitated using the chloramine $\mathrm{T}$ method as described before [22] with minor modifications. In brief, liver specimens $(1 \mathrm{mg})$ were hydrolyzed in $2 \mathrm{ml}$ of $6 \mathrm{~N} \mathrm{HCl}$ at $100{ }^{\circ} \mathrm{C}$ for $12 \mathrm{~h}$. After centrifugation at $3000 \mathrm{rpm}$ for $10 \mathrm{~min}$, the hydrolysate was neutralized with $6 \mathrm{~N} \mathrm{NaOH}$, and centrifuged at $13,000 \mathrm{~g}$ for $12 \mathrm{~min}$. Fresh prepared Chloramine T solution $(1 \mathrm{ml})$ were added to the neutralized supernatant $(1 \mathrm{ml})$ and incubated at room temperature for $10 \mathrm{~min}$. Ehrlich's solution $(4 \mathrm{ml})$ was then added and incubated for $15 \mathrm{~min}$ at $65^{\circ} \mathrm{C}$. The absorbance was transferred to a plastic tube after cooling and measured at $560 \mathrm{~nm}$. Hydroxyproline concentration was expressed as micrograms of hydroxyproline per gram of liver.

\section{Biochemical analysis}

Serum was separated by centrifugation within $1 \mathrm{~h}$ of blood collection when the rats were sacrificed and stored at $-20^{\circ} \mathrm{C}$ until analyzed. Serum levels of aspartate transaminase (AST), alanine transaminase (ALT), and total bilirubin (T-BiL) were determined using an Automated Chemical Analyzer (7600; Hitachi, Tokyo, Japan) according to the manufacturer's instructions.

\section{Statistical analysis}

All measurements were repeated three times, and results are expressed as the mean \pm SD. Differences between two groups were compared with Student's t-test. Groups were compared with one-way ANOVA test. $\mathrm{P}<0.05$ was 
considered statistically significant. Statistical analysis was run with SPSS 13.0.

\section{Results}

Isolation and identification of ADMSCs

ADMSCs were isolated from SD rat inguinal fat pad, and proliferating cells were enriched as described before. ADMSCs had spindle-shaped morphological feature in ten days culture (Figure 1A).

We measured the expression of surface marker. The fifth passage of ADMSCs expressed CD29, CD44 and CD90, and were negative of CD34 and CD45 (Figure 1B)

\section{ADMSC transplantation improved microcirculation in fibrotic liver}

All rats survived the 12 week $\mathrm{CCl}_{4}$ administration. We performed CT perfusion scan on experimental subjects to measure the alteration of liver microcirculation. The measurements of HAP, PVP, TLP and HPI suggested significantly decreased portal venous and total liver perfusion, and significant increase of hepatic arterial to total hepatic perfusion ratio, compared with that of healthy controls, indicating microcirculation impairment in fibrotic models and relative compensation of blood supply with hepatic arterial perfusion (Table 1).

ADMSC transplantation improved microcirculation in fibrotic liver. SD rats with liver fibrosis were randomly divided into three subgroups: one was given irrelevant cells as control; the other two were given the same dosage of ADMSCs, in portal vein and tail vein respectively.
Table 1 Comparison between normal rats and fibrotic models (12 weeks $\mathrm{CCl}_{4}$ ) on perfusion parameters

\begin{tabular}{lcccc}
\hline & HAP & PVP & TLP & HPI \\
\hline Normal subjects $(n=12)$ & $26.4 \pm 8.2$ & $120.3 \pm 39.8$ & $146.7 \pm 43.3$ & $18.0 \pm 3.7$ \\
Fibrotic models $(n=12)$ & $49.2 \pm 19.2 *$ & $31.4 \pm 9.3 *$ & $80.5 \pm 26.8 *$ & $61.1 \pm 22.2$
\end{tabular}

Values are expressed as mean \pm SD.

${ }^{*} \mathrm{P}<0.05$, Fibrotic models versus Normal rats.

PVP: Portal vein perfusion $(\mathrm{mL} / \mathrm{min}$ per $100 \mathrm{~mL}$ ); HAP: Hepatic artery perfusion $(\mathrm{mL} / \mathrm{min}$ per $100 \mathrm{~mL})$.

TLP: Total liver perfusion ( $\mathrm{mL} / \mathrm{min}$ per $100 \mathrm{ml}$ ); HPI: Hepatic artery perfusion index (\%).

After $\mathrm{CCl}_{4}$ administration for 18 weeks and ADMSCs/ placebo treatment, 6 rats died in the irrelevant cells group (60\% survival), 4 rats died in the tail vein group (73\% survival), and only 1 rat died in the portal vein group (93\% survival).

We performed CT perfusion scan after treatment protocols. HPI were significantly decreased in rats receiving ADMSCs from portal vein (Group B), while PVP and TLP were significantly increased $(p<0.05)$ compared with baseline. No significance $(p>0.05)$ was found in rats receiving ADMSCs from tail vein (Group C), though the data seemed change with the same tendency as group B. The data indicated liver microcirculation improvement was significantly observed in ADMSC portal vein group, but neither in ADMSC tail vein group or irrelevant cells portal vein group (Table 2).

To further explore angiogenesis in fibrotic models, microvessels were highlighted with anti-factor VIII antibody (Figure 2A-E), a specific marker for endothelial cells,

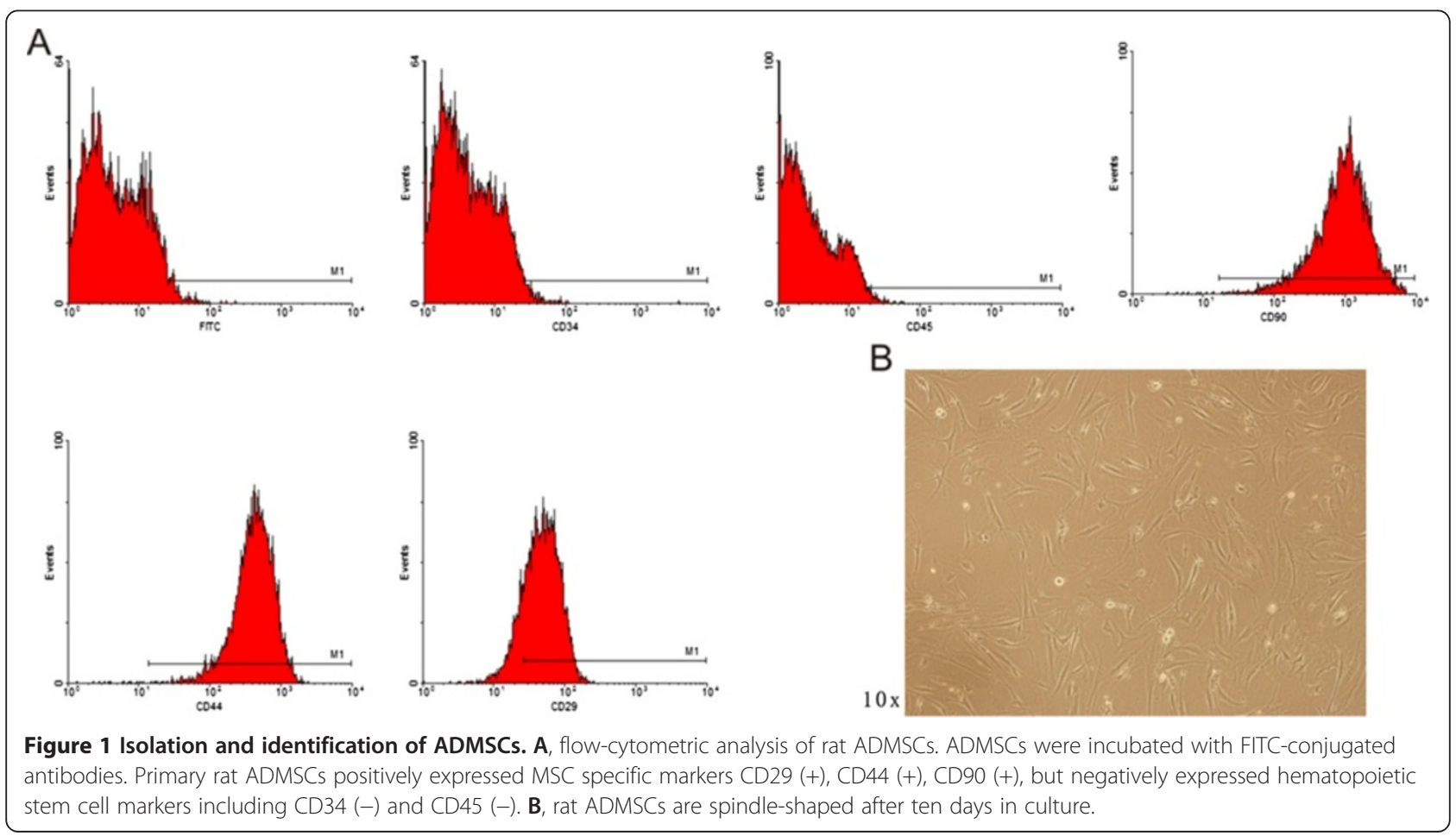


and quantified as microvessels counts expressed in fold control (Figure 2F). There was a significant increase of FVIII positive hepatic microvascular staining in $\mathrm{CCl}_{4}$ induced cirrhosis models. Hepatic microvessel counts showed substantial decrease of FVIII staining in portal venous ADMSC group. No significant change was observed in tail vein ADMSC group. We examined VEGF expression at gene (Figure 2G) and protein (Figure 2H) level. As an angiogenesis marker, hepatic VEGF upregulation was detected in $\mathrm{CCl}_{4}$ induced fibrotic models. After ADMSCs/placebo treatment, VEGF levels were significantly lower in ADMSC portal vein group than in ADMSC tail vein group or irrelevant cells control portal vein group, suggesting the up-regulation of VEGF triggered by restricted blood supply of liver fibrosis could be partially converted by effective ADMSC transplantation.

\section{Effects of ADMSCs transplantation on liver function tests} Pre- and post-therapy laboratory findings suggested the protection capability of ADMSCs. Serum ALT, AST and T-BiL were significantly higher, and ALB was significantly lower in fibrotic models (data not shown). After ADMSCs transplantation (Figure 3), a significant decline in ALT $(518 \pm 189 \mathrm{U} / \mathrm{L}$ versus $229 \pm 76 \mathrm{U} / \mathrm{L}$ for before and after therapy, $P<0.05)$, AST $(689 \pm 275 \mathrm{U} / \mathrm{L}$ versus $316 \pm 87 \mathrm{U} / \mathrm{L}$ for before and after therapy, $P<0.05)$ and serum bilirubin $(13.6 \pm 4.1 \mathrm{umol} / \mathrm{L}$ versus $5.6 \pm 2.2 \mathrm{umol} /$ $\mathrm{L}$ for before and after therapy, $P<0.05)$ and a significant increase of ALB $(16.2 \pm 4.8 \mathrm{~g} / \mathrm{L}$ versus $27.4 \pm 5.3 \mathrm{~g} / \mathrm{L}$ for before and after therapy, $P<0.05)$ was observed in portal vein group (Group B). No significant changes were found in saline portal vein group or ADMSC tail vein group.

\section{Liver fibrosis suppression by ADMSCs transplantation}

Liver fibrosis induced by $\mathrm{CCl}_{4}$ and after ADMSCs transplantation was evluated using H\&E staining (Figure 4A), Sirius red staining (Figure 4B), Sirius red staining quantification (Figure $4 \mathrm{C}$ ) and hydroxyproline measurement (Figure 4D). In normal control, collagen fibers were observed only in the periportal area. $\mathrm{CCl}_{4}$ treatment aroused fibrotic septa, pseudolobuli, hepatic steatosis and necrosis of liver cells. Sirius red stained collagen was significantly increased after $\mathrm{CCl}_{4}$ treatment. Portal venous implantation of ADMSCs significantly reduced steatosis lesions, alleviated necrosis, and relatively suppressed bridging fibrotic septa. Three weeks after implantation, the Sirius red positive area were gradually reduced. Six weeks after implantation, a significant decrease in collagen was noted in the ADMSCs treated group compared to the untreated rats $(4.73 \% \pm 1.17 \%$ vs $11.43 \% \pm 3.16 \%, \quad \mathrm{P}<0.05)$. Tail vein implantation of ADMSCs reduced steatosis lesions, but failed to decrease the collagen content significantly as expressed by quantification of Sirius red staining. Hydroxyproline content changes paralleled the extent of fibrosis. ADMSCs portal venous transplantation blocked the $\mathrm{CCl}_{4}$ induced hydroxyproline content increase in liver, indicating significant decrease of collagen deposition. The amount of collagen slightly dropped in tail vein transplantation group, but no significance was observed.

\section{Discussion}

MSCs are currently investigated as an alternative therapy for liver transplantation in end-stage liver diseases including severe liver fibrosis. MSCs have also been proved to be a potential solution in severe liver injury such as ischemia-reperfusion injury [23], acute liver failure [24], or hepatocellular carcinoma [25].

Studies have shown that MSCs existed in various human tissues [26,27], and have the ability to differentiate into hepatocyte in inducing medium $[28,29]$.

Carbon tetrachloride $\left(\mathrm{CCl}_{4}\right)$-induced liver fibrosis in rodents was reported to be prevented receiving MSC transplantation [30-32].

Adipose tissue derived mesenchymal stem cells (ADMSCs), as a source of MSC, exhibit similar differentiation and multi-functional abilities as bone marrow MSC, are better immuno-compatible, much easier to isolate and expand. ADMSCs may provide a new approach for hepatic fibrosis therapy.

In the present study, ADMSCs were isolated from SD rat inguinal fat pad and identified by surface antigen tests. Purified ADMSCs positively expressed MSC markers CD29, CD44 and CD90, whereas negatively expressed hematopoietic stem cell markers CD34 and

Table 2 CT perfusion parameters of before and after therapy in test and control group

\begin{tabular}{|c|c|c|c|c|c|c|c|c|}
\hline & \multicolumn{2}{|c|}{ PVP } & \multicolumn{2}{|r|}{ HAP } & \multicolumn{2}{|c|}{ TLP } & \multicolumn{2}{|c|}{ HPI } \\
\hline & Before the & After therapy & Before the & apy After therapy & Before therapy & After therapy & Before the & py After therapy \\
\hline Irrelevant cells $(n=9)$ & $33.2 \pm 8.5$ & $26.5 \pm 7.9$ & $53.3 \pm 17.0$ & $51.8 \pm 17.3$ & $86.5 \pm 29.3$ & $78.3 \pm 34.5$ & $61.6 \pm 19.9$ & $66.1 \pm 21.3$ \\
\hline Portal vein $(n=14)$ & $33.4 \pm 11.0$ & $65.8 \pm 15.9^{*}$ & $48.4 \pm 19.4$ & $51.2 \pm 23.9$ & $81.9 \pm 24.4$ & $117.0 \pm 37.4^{*}$ & $59.2 \pm 20.4$ & $43.7 \pm 15.9^{*}$ \\
\hline Tail vein & $29.2 \pm 8.0$ & $33.5 \pm 10.0$ & $47.3 \pm 22.8$ & $50.4 \pm 22.8$ & $76.5 \pm 29.6$ & $83.9 \pm 32.3$ & $61.8 \pm 26.3$ & $60.0 \pm 25.5$ \\
\hline
\end{tabular}

Values are expressed as mean \pm SD.

${ }^{*} \mathrm{P}<0.05$, after therapy versus before therapy.

PVP: Portal vein perfusion (mL/min per $100 \mathrm{~mL}$ ); HAP: Hepatic artery perfusion $(\mathrm{mL} / \mathrm{min}$ per $100 \mathrm{~mL})$

TLP: Total liver perfusion (mL/min per $100 \mathrm{ml}$ ); HPI: Hepatic artery perfusion index $(\%)$. 

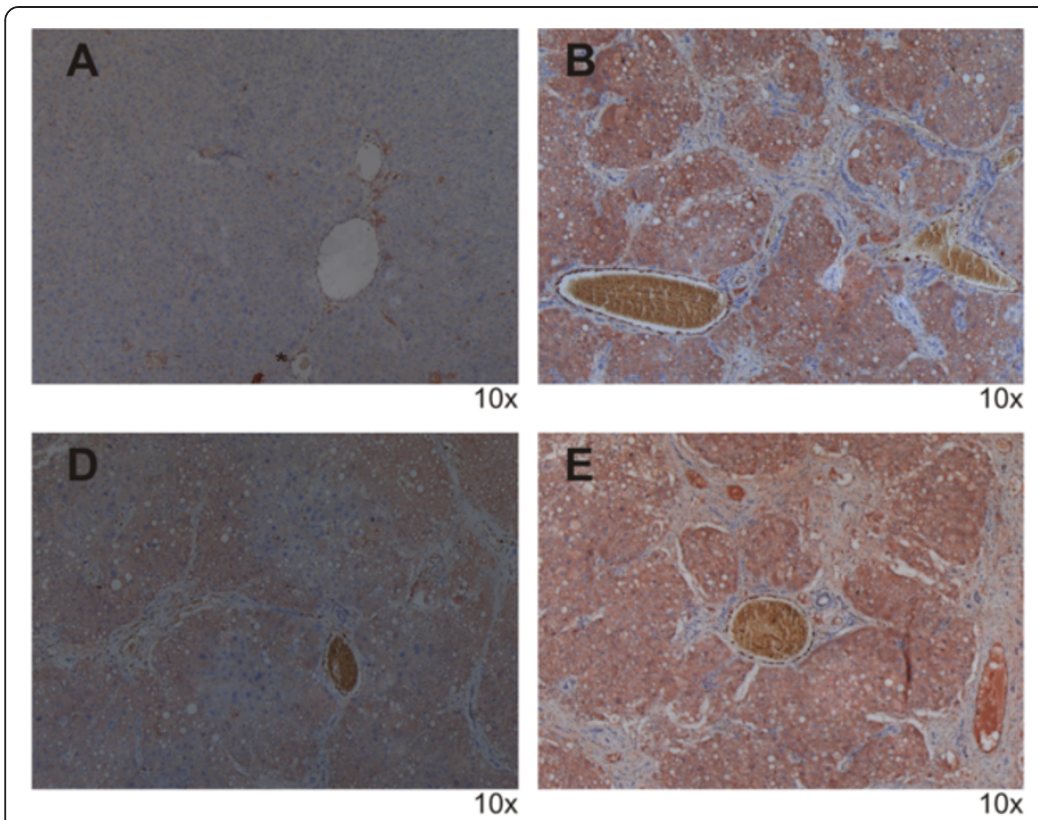

G
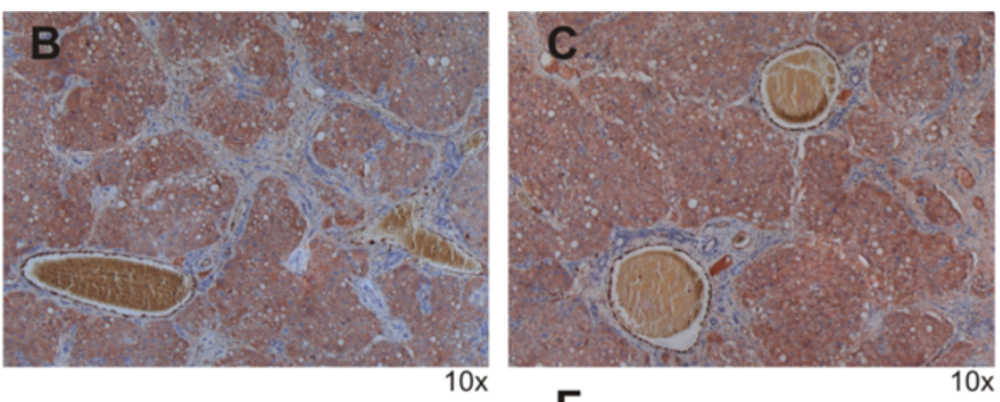

$\mathbf{F}$

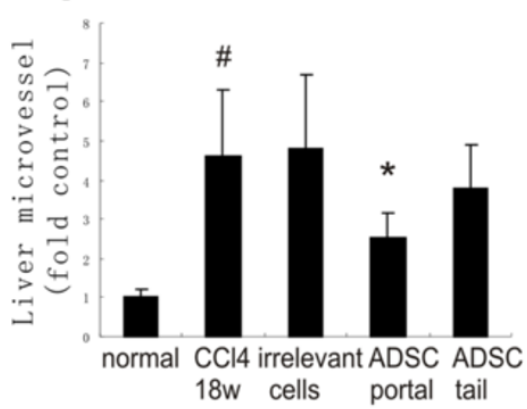

H

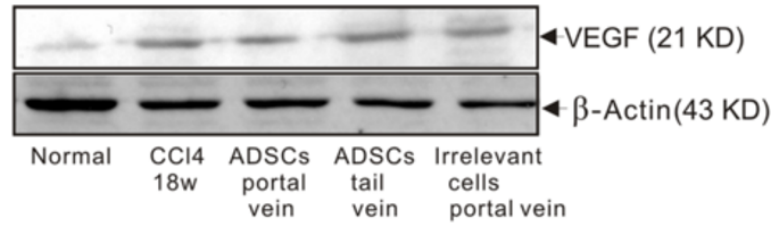

Figure 2 Agiogenesis after ADMSC transplantation. Immunohistochemical staining of factor VIII (FVIII) and microvessel counts. A, normal control. B, 18 weeks of $\mathrm{CCl}_{4}$ administration. $\mathbf{C}$, portal venous injection of irrelevant cells. D, portal vein ADMSC transplantation. $\mathbf{E}$, tail vein ADMSC transplantation. $\mathbf{F}$, microvessel counts. ADMSCs portal vein transplantation decreases VEGF expression in the fibrotic liver at gene and protein level. G, qPCR examination. $\mathbf{H}$, Western blotting. ${ }^{*} \mathrm{p}<0.05$ versus 18 weeks of $\mathrm{CCl}_{4}$ administration; $\# \mathrm{p}<0.05$ between normal control and $\mathrm{CCl} \mathrm{l}_{4}$ treatment $(18 \mathrm{~W})$.

CD45. Previous studies have proved the long term survival of ADMSCs engraftment in liver parenchyma $[8,33]$.

In the present study, when transplanted with ADMSCs, $\mathrm{CCl}_{4}$-induced fibrosis SD rats exhibited microcirculation changes under $\mathrm{CT}$ perfusion scan. Significant increase of blood supply was observed in portal vein group (Group B). Interestingly, no significance was found in tail vein group (Group C). Liver function tests and histological examination revealed the same tendency, which was not well in accordance with the study by Rabani $\mathrm{V}$ et al, who reported tail vein transplantation of MSCs helped to reduce liver fibrosis [34].

CT perfusion was a non-invasive technique to sensitively detect hemodynamic changes in liver tissue. Since Miles et al. reported the possibility to analyze hepatic perfusion using slice dynamic CT scan [35], researches have managed to access capillary blood alteration using this method.

As we have shown in Table 1, reduced portal and total perfusion was observed in fibrosis models, relatively compensated by increase of hepatic arterial flow. The blockage of liver microcirculation due to collagen deposit and active remodeling may increase intrahepatic vascular resistance and exacerbate the disease progression. We demonstrated that portal venous ADMSC implantation benefited liver fibrosis by significantly increasing PVP and TLP (Table 2). FVIII staining and quantification confirmed the significant decrease of microvessel counts after ADMSC portal venous transplantation, supporting the idea that angiogenesis in $\mathrm{CCl}_{4}$ induced fibrosis model could be reversed by ADMSC 

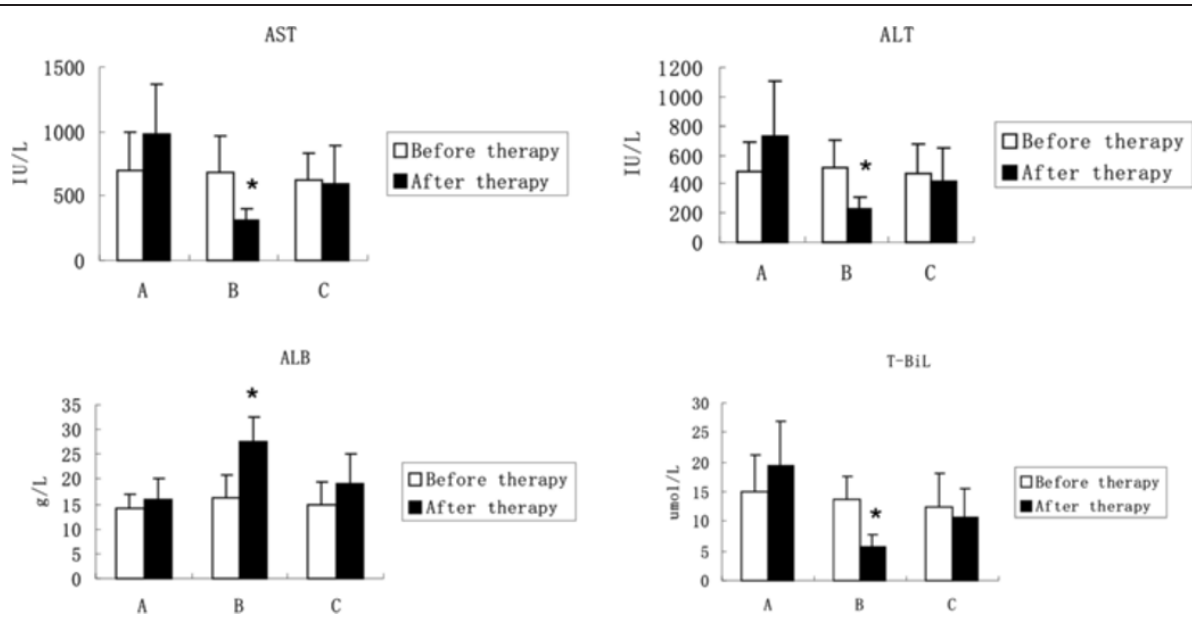

Figure 3 Liver function test values. The histograms show AST, ALT, ALB and T-BiL changes before and after placebo/ADMSCs infusion in 3 different groups (A, the control group without ADMSCS; B, The portal vein group with ADMSCs; and $\mathbf{C}$, The tail vein group with ADMSCs). Values are expressed as mean $\pm \mathrm{SD}$. ${ }^{*} \mathrm{P}<0.05$, after therapy versus before therapy..

treatment. The therapeutic mechanism of MSC for preventing liver fibrosis is not clear. Some have reported its function by effecting MMPs [34], or by suppressing inflammation and immunoreaction [36]. Importantly, MSCs were described in previous study having the ability to modulate VEGF delivery, differentiate into

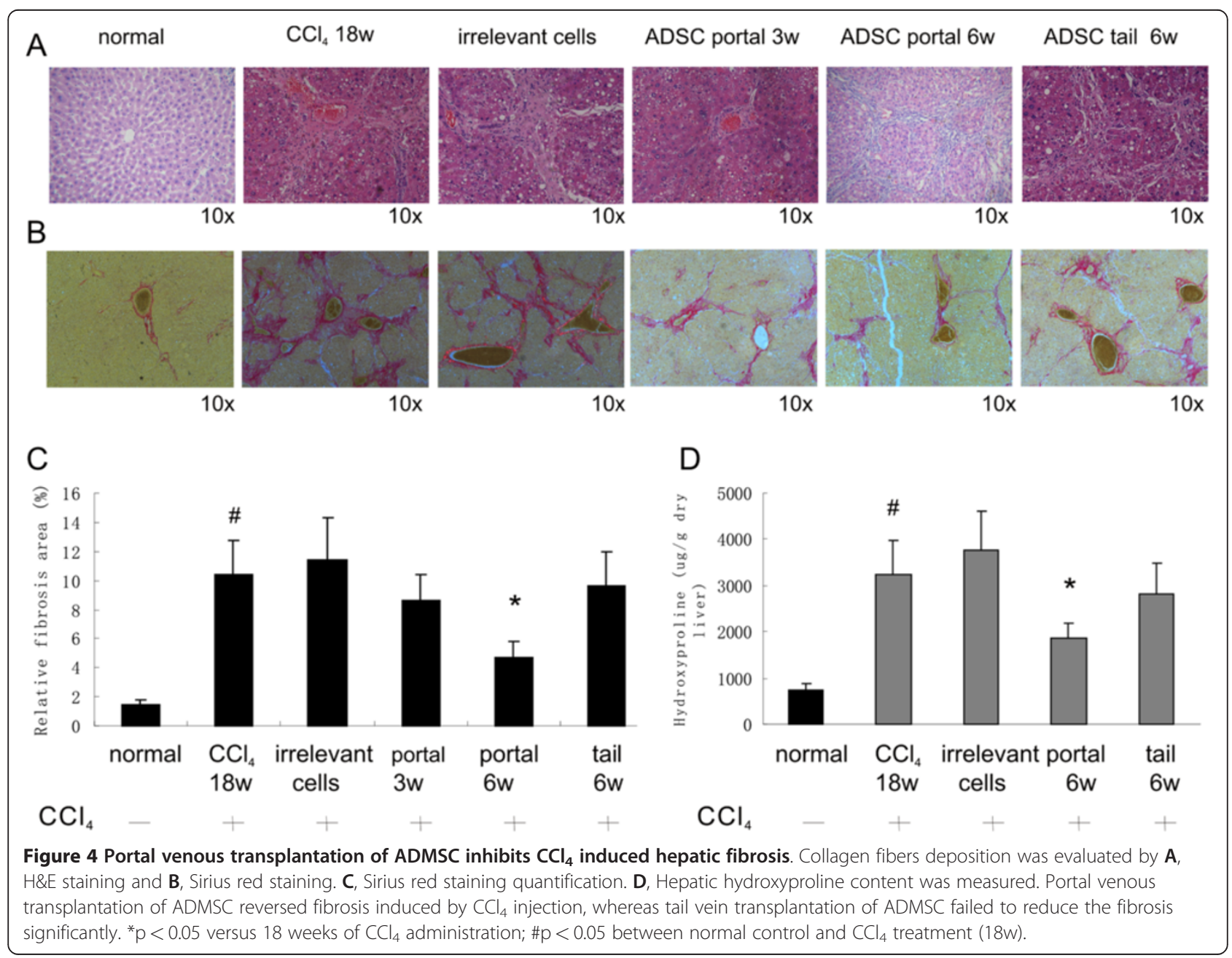


endothelial-like cells and anastomose with the host vasculature [37-40]. We observed significantly increased expression of VEGF at mRNA and protein level in fibrosis models, and the suppression of fibrosis by ADMSCs transplantation resulted in down regulation of VEGF. VEGF is one of the most central factors of angiogenesis and sinusoidal capillarisation in liver fibrosis [41,42]. VEGF and its receptor intensively expressed and interacted with activated HSC (hepatic stellate cell), which plays an important role in liver fibrosis development [43-45]. Extensive fibrosis related to hypoxemia or less blood supply may be a strong stimulator to VEGF production [46]. And decrease fibrosis contributing to modification of liver bloody supply may be accompanied by VEGF down regulation [47]. Our data correlated the angiogenesis marker VEGF to microcirculation improvement exhibited on CT perfusion scan, which helped to explain the underlying mechanism of fibrosis attenuation caused by ADMSC implantation.

There are still controversies about the most appropriate route of MSC transplantation. In our study, the effectiveness of different transplantation routes was compared. Kim SJ and co-workers have reported that tail vein transplantation was more effective than portal vein transplantation [48]. However, in our case, portal vein ADMSC implantation was documented significantly more blood supply alteration as that of tail vein implantation in CT perfusion scan. As is also revealed in histological findings, tail vein group had no improvement in fibrogenesis, but only reduced steatosis lesions, while portal vein group exhibited much more therapeutic potential. In the case of tail vein transplantation for MSC grafting, stem cells may not concentrate and disperse throughout the target organ, thus significantly less MSCs would reach liver and induce therapeutic effect in the target organ [49]. Portal venous infusion helped to mechanically trap grafted cells when they particularly present along sinusoids [48], thus raise the efficiency of ADMSC transplantation.

The efficacy and feasibility of MSC portal vein transfusion has been reported by other researches [50,51]. And as we observed, the results demonstrated a therapeutic advantage of intraportal infusion over peripheral venous infusion.

As discussed above, our data suggested that ADMSCs was easily accessible and expandable. Transplantation via portal vein gave their ability to improve microcirculation and ameliorate liver fibrosis. Future work will be required to explore deeply into the mechanism of how ADMSCs reduce fibrosis and evaluate the therapeutic potential of ADMSCs treatment in clinical settings.

\section{Conclusion}

In conclusion, the present study suggested a protective role of ADMSCs in liver fibrosis, evidenced by increasing portal and total blood supply viewed in CT perfusion scan, decreased VEGF expression at mRNA and protein level, as well as improved liver function tests and hepatic biopsy. CT perfusion scan was a sensitive and non-invasive method to monitor therapeutic effect in recipient liver. In addition, we have also found that intraportal transplantation was a more appropriate pathway than tail vein transplantation.

\section{Competing interests}

The authors declare that they have no competing interests.

\section{Authors' contributions}

WY and LF carried out the molecular genetic studies, animal experiments, participated in the sequence alignment and drafted the manuscript. WY and LF equally contributed to this publication. LJ participated in the animal experiments. FW carried out the immunoassays. $\mathrm{XH}$ helped to draft the manuscript. $L L$ and $Y X$ performed the statistical analysis. CW ran the GPCR. YJ participated in the design of the study, coordinated and helped to draft the manuscript. All authors read and approved the final manuscript.

\section{Acknowledgement}

Project 81102270 and 81101135 supported by National Natural Science Foundation of China. Project 11ykpy 15 and 11 ykpy 18 supported by the Fundamental Research Funds for the Central Universities.

\section{Author details}

${ }^{1}$ Department of Interventional Oncology, the First Affiliated Hospital of Sun Yat-sen University, No. 58, Zhongshan 2nd Road, Guangzhou 510080, China. ${ }^{2}$ Department of Rheumatology \& Clinical Immunology, the First Affiliated Hospital of Sun Yat-sen University, No. 58, Zhongshan 2nd Road, Guangzhou 510080, China. ${ }^{3}$ Department of Interventional Radiology, the First Affiliated Hospital of Sun Yat-sen University, No. 58, Zhongshan 2nd Road, Guangzhou 510080, China. ${ }^{4}$ Department of Medical Imaging, the First Affiliated Hospital of Sun Yat-sen University, No. 58, Zhongshan 2nd Road, Guangzhou 510080, China.

Received: 13 March 2012 Accepted: 19 June 2012

Published: 26 June 2012

\section{References}

1. Friedman SL: Liver fibrosis-from bench to bedside. J Hepato/ 2003, 38 (Suppl.1):S38-S53.

2. Gines P, Cardenas A, Arroyo V, et al: Management of cirrhosis and ascites. N Engl J Med 2004, 350:1646-1654.

3. Iredale JP: Models of liver fibrosis: exploring the dynamic nature of inflammation and repair in a solid organ. J Clin Invest 2007, 117(3):539-548.

4. Fallowfield JA, Iredale JP: Targeted treatments for cirrhosis. Expert Opin Ther Targets 2004, 8:423-425.

5. Ortiz LA, Gambelli F, McBride C, et al: Mesenchymal stem cell engraftment in lung is enhanced in response to bleomycin exposure and ameliorates its fibrotic effects. Proc Natl Acad Sci U S A 2003, 100(14):8407-8411.

6. Sakaida I, Terai S, Yamamoto N, et al: Transplantation of bone marrow cells reduces CCl4-induced liver fibrosis in mice. Hepatology 2004, 40 (6):1304-1311.

7. Deans RJ, Moseley AB: Mesenchymal stem cells: biology and potential clinical uses. Exp Hematol 2000, 28:875-884

8. Liang L, Ma T, Chen W, et al: Therapeutic potential and related signal pathway of adipose-derived stem cell transplantation for rat liver injury. Hepatol Res 2009, 39(8):822-832.

9. Schaffler A, Buchler C: Concise review: adipose tissue-derived stromal cells-basic and clinical implications for novel cell-based therapies. Stem Cells 2007, 25(4):818-827.

10. Khan WS, Adesida AB, Tew SR, et al: The epitope characterization and the osteogenic differentiation potential of human fat pad-derived stem cells is maintained with ageing in later life. Injury 2009, 40(2):150-157.

11. Oedayrajsingh-Varma MJ, van Ham SM, Knippenberg M, et al: Adipose tissue-derived mesenchymal stem cell yield and growth characteristics 
are affected by the tissue-harvesting procedure. Cytotherapy 2006, 8:166-177.

12. Safford KM, Hicok KC, Safford SD, et al: Neurogenic differentiation of murine and human adipose-derived stromal cells. Biochem Biophys Res Commun 2002, 294:371-379.

13. Mitchell JB, Mclntosh K, Zvonic S, et al: Immnophenotype of Human Adipose-Derived Cells: Temporal Changes in Stromal-Associated and Stem Cell-Associated Markers. Stem Cells 2006, 24:376-385.

14. Aurich $H$, Sgodda M, Kaltwasser $P$, et al: Hepatocyte differentiation of mesenchymal stem cells from human adipose tissue in vitro promotes hepatic integration in vivo. Gut 2009, 58(4):570-581.

15. Liu F, Liu ZD, Wu N, et al: Transplanted endothelial progenitor cells ameliorate carbon tetrachloride-induced liver cirrhosis in rats. Liver Transp/ 2009, 15(9):1092-1100.

16. Dong $\mathrm{MX}$, Jia $Y$, Zhang $Y B$, et al: Emodin protects rat liver from $\mathrm{CCl}_{4}$ induced fibrogenesis via inhibition of hepatic stellate cells activation. World J Gastroenterol 2009, 15(38):4753-4762.

17. Varga F, Mehes G, Molnar Z: Reversibility of hepatic fibrosis induced by carbon tetrachloride in the rat. Acta Physiol Acad Sci Hung 1996, 29:69-74.

18. Materne R, Van Beers BE, Smith AM, et al: Non-invasive quantification of liver perfusion with dynamic computed tomography and a dual-input one-compartmental model. Clin Sci (Lond) 2000, 99:517-525.

19. Van Beers BE, Leconte I, Materne $R$, et al: Hepatic perfusion parameters in chronic liver disease: dynamic CT measurements correlated with disease severity. Am J Roentgenol 2001, 176:667-673.

20. Yang ZF, Ho DW, Chu AC, et al: Linking inflammation in small-for-size allografts: the potential role of early macrophage activation. Am J Transplant 2004, 4:196

21. Liu MY, Poellinger $L$, Walker CL: Up-regulation of hypoxia-inducible factor 2alpha in renal cell carcinoma associated with loss of Tsc- 2 tumor suppressor gene. Cancer Res 2003, 63:2675-2680.

22. Gandhi $\mathrm{CR}$, Kuddus $\mathrm{RH}$, Nemoto EM, et al: Endotoxin treatment causes an up-regulation of the endothelin system in the liver: Amelioration of increased portal resistance by endothelin receptor antagonism. J Gastroenterol Hepatol 2001, 16:61-69.

23. Sun CK, Chang CL, Lin YC, et al: Systemic administration of autologous adipose-derived mesenchymal stem cells alleviates hepatic ischemiareperfusion injury in rats. Crit Care Med 2012, 40(4):1279-1290.

24. Yukawa H, Noguchi $H$, Oishi $K$, et al: Cell transplantation of adipose tissuederived stem cells in combination with heparin attenuated acute liver failure in mice. Cell Transplant 2009, 18(5):611-618.

25. Abdel aziz MT, El Asmar MF, Atta HM, et al: Efficacy of mesenchymal stem cells in suppression of hepatocarcinorigenesis in rats: possible role of Wnt signaling. J Exp Clin Cancer Res 2011, 30:49.

26. Baertschiger RM, Bosco D, Morel P, et al: Mesenchymal stem cells derived from human exocrine pancreas express transcription factors implicated in beta-cell development. Pancreas 2008, 37(1):75-84.

27. Meyerrowe TE, De Ugarte DA, Hofling AA, et al: In vivo distribution of human adipose-derived mesenchymal stem cells in novel xenotransplantation models. Stem Cells 2007, 25(1):220-227.

28. Ren $\mathrm{H}$, Zhao Q, Cheng $\mathrm{T}$, et al: No contribution of umbilical cord mesenchymal stromal cells to capillarization and venularization of hepatic sinusoids accompanied by hepatic differentiation in carbon tetrachlorideinduced mouse liver fibrosis. Cytotherapy 2010, 12(3):371-383.

29. Lee KD, Kuo TK, Whang-Peng J, et al: In vitro hepatic differentiation of human mesenchymal stem cells. Hepatology 2004, 40(6):1275-1284.

30. Oyagi S, Hirose M, Kojima M, et al: Therapeutic effect of transplanting HGF-treated bone marrow mesenchymal cells into $\mathrm{CCl}_{4}$-injured rats. J Hepatol 2006, 44(4):742-748.

31. Aquino JB, Bolontrade MF, García MG, et al: Mesenchymal stem cells as therapeutic tools and gene carriers in liver fibrosis and hepatocellular carcinoma. Gene Ther 2010, 17(6):692-708.

32. Ishikawa T, Terai S, Urata $Y$, et al: Administration of fibroblast growth factor 2 in combination with bone marrow transplantation synergistically improves carbon-tetrachloride-induced liver fibrosis in mice. Cell Tissue Res 2007, 327(3):463-470.

33. Kamada $Y$, Yoshida $Y$, Saji $Y$, et al: Transplantation of basic fibroblast growth factor-pretreated adipose tissue-derived stromal cells enhances regression of liver fibrosis in mice. Am J Physiol Gastrointest Liver Physiol 2009, 296(2):G157-G167.
34. Rabani $V$, Shahsavani $M$, Gharavi $M$, et al: Mesenchymal stem cell infusion therapy in a carbon tetrachloride-induced liver fibrosis model affects matrix metalloproteinase expression. Cell Biol Int 2010, 34(6):601-605.

35. Miles KA, Hayball MP, Dixon AK: Functional images of hepatic perfusion obtained with dynamic CT. Radiology 1993, 88:405-411.

36. Pulavendran S, Vignesh J, Rose C: Differential anti-inflammatory and antifibrotic activity of transplanted mesenchymal vs. hematopoietic stem cells in carbon tetrachloride-induced liver injury in mice. Int Immunopharmacol 2010, 10(4):513-519.

37. Moioli EK, Paul A, et al: Synergistic actions of hematopoietic and mesenchymal stem/progenitor cells in vascularizing bioengineered tissues. PLoS One 2008, 31(12):e3922.

38. Kestendjieva S, Kyukchiev D, Tsvetkova G, et al: Characterization of mesenchymal stem cells isolated from the human umbilical cord. Cell Biol Int 2008, 32:724-732.

39. Yue WM, Liu W, Bi YW, et al: Mesenchymal stem cells differentiate into an endothelial phenotype, reduce neointimal formation, and enhance endothelial function in a rat vein grafting model. Stem Cells Dev 2008, 17:785-794.

40. Tang J, Xie Q, Pan G, et al: Mesenchymal stem cells participate in angiogenesis and improve heart function in rat model of myocardial ischemia with reperfusion. Eur J Cardiothorac Surg 2006, 30:353-361.

41. Rosmorduc O, Wendum D, Corpechot C, et al: Hepatocellular hypoxiainduced vascular endothelial growth factor expression and angiogenesis in experimental biliary cirrhosis. Am J Pathol 1999, 155:1065-1073.

42. Cui S, Hano H, Sakata A, et al: Enhanced CD34 expression of sinusoid-like vascular endothelial cells in hepatocellular carcinoma. Pathol Int 1996, 46:751-756.

43. Ishikawa K, Mochida S, Mashiba S, et al: Expressions of vascular endothelial growth factor in nonparenchymal as well as parenchymal cells in rat liver after necrosis. Biochem Biophys Res Commun 1999, 254:587-593.

44. Arthur MJ, Mann DA, Iredale JP: Tissue inhibitors of metalloproteinases, hepatic stellate cells and liver fibrosis. J Gastroenterol Hepatol 1998, 13 (suppl):S33-S38.

45. Ankoma-Sey $V$, Wang $Y$, Dai Z: Hypoxic stimulation of vascular endothelial growth factor expression in activated rat hepatic stellate cells. Hepatology 2000, 31:141-148.

46. Raleigh JA, Calkins-Adams DP, Rinker LH, et al: Hypoxia and vascular endothelial growth factor expression in human squamous cell carcinomas using pimonidazole as a hypoxia marker. Cancer Res 1998 58:3765-3768

47. Shi BM, Wang $X Y, M u Q L$, et al: Expression of vascular endothelial growth factor in cirrhotic tissues and their relations to proto-oncogene c-fos, c-myc. Hepatobiliary Pancreat Dis Int 2002, 1(3):388-391.

48. Kim SJ, Park KC, Lee JU, et al: Therapeutic potential of adipose tissuederived stem cells for liver failure according to the transplantation routes. J Korean Surg Soc. 2011, 81(3):176-186.

49. Bos C, Delmas Y, Desmouliere, et al: In vivo MR imaging of intravascularly injected magnetically labeled mesenchymal stem cells in rat kidney and liver. Radiology 2004, 233:781-789.

50. Yu Y, Lu L, Qian X, et al: Antifibrotic effect of hepatocyte growth factor expressing mesenchymal stem cells in a smal-for-size liver transplant rats. Stem Cells Dev 2010, 19(6):93-03-14.

51. Chang YJ, Liu JW, Lin PC, et al: Mesenchymal stem cells facilitate recovery from chemically induced liver damage and decrease liver fibrosis. Life Sci 2009, 85(13-14):517-525

\section{doi:10.1186/1479-5876-10-133}

Cite this article as: Wang et al:: Adipose derived mesenchymal stem cells transplantation via portal vein improves microcirculation and ameliorates liver fibrosis induced by $\mathrm{CCl} 4$ in rats. Journal of Translational Medicine 2012 10:133. 